\title{
EVALUACIÓN DE LAS PRÁCTICAS DE ORDEÑO, LA CALIDAD HIGIÉNICA Y NUTRICIONAL DE LA LECHE, EN EL MUNICIPIO DE GRANADA, ANTIOQUIA - COLOMBIA
}

\section{ASSESSMENT PRACTICES MILKING, HYGIENIC AND NUTRITIONAL QUALITY OF MILK IN THE MUNICIPALITY OF GRANADA, ANTIOQUIA - COLOMBIA}

\author{
Roberto Silva Pulido ${ }^{1}$, Juliana Alzate Amelines ${ }^{2}$, Claudia Reyes Manosalva ${ }^{3}$
}

\begin{abstract}
${ }^{1}$ Zootecnista. Esp. Centro de la Innovación la Agroindustria y el Turismo SENA. JRE. Rionegro, Antioquia, e-mail: rsilvapulido@misena.edu.co; ${ }^{2}$ Zootecnista. Centro de la Innovación la Agroindustria y el Turismo SENA JRE. Rionegro, Antioquia, e-mail: mijuliana@misena.edu.co; ${ }^{3}$ Ingeniera de Producción Agroindustrial. Centro de la Innovación la Agroindustria y el Turismo SENA. Rionegro, Antioquia, e-mail: cyreyesm@misena.edu.co
\end{abstract}

Rev. U.D.C.A Act. \& Div. Cient. 17(2): 467-475, Julio-Diciembre, 2014

\section{RESUMEN}

La calidad de la leche se ve afectada por la mastitis y por las prácticas empleadas durante y después del ordeño. El propósito de este estudio fue evaluar las prácticas de ordeño y la calidad higiénica y nutricional de la leche producida en Granada, Antioquia. Mediante muestreo no probabilístico, se seleccionaron diez fincas productoras, pertenecientes a ASOGRAN. La evaluación de las prácticas de ordeño fue realizada mediante observación directa y, la detección de mastitis, se hizo en cada finca, utilizando la Prueba California (CMT). Al finalizar el ordeño, se tomaron dos muestras de leche, con un intervalo de 60 días, efectuándose análisis de unidades formadoras de colonia (UFC), conteo células somáticas (CCS), porcentajes de proteína, grasa y sólidos totales; durante este intervalo, se capacitaron los productores en buenas prácticas de ordeño (BPO). Los análisis estadísticos, se realizaron mediante la prueba Wilcoxon. Antes de la capacitación, se registró incumplimiento en las actividades de las BPO; se hallaron diferencias significativas para las pruebas de mastitis y de UFC antes y después de la capacitación; además, el $24 \%$ de las glándulas mamarias, se percibían afectadas por mastitis subclínica. En la calidad higiénica de la leche, se encontró UFC promedio de $6 \times 10^{5}$ y $3 \times 10^{5}$, respectivamente. El CCS no presentó diferencias significativas, reportando valores promedio de 630.000 y 750.000 , respectivamente. La calidad nutricional reportó porcentajes de grasa, proteína y sólidos totales, superiores a los exigidos en la legislación colombiana. Los hallazgos indican la importancia de la aplicación de las BPO sobre la calidad de la leche.

\section{SUMMARY}

Milk quality is affected by mastitis and practices used during and after milking. The purpose of this study was to evaluate milking practices, hygienic and nutritional quality of milk produced in Granada, Antioquia, by no probabilistic sampling, ten farms belonging to the association ASOGRAN were selected. Assessment of milking practices was realized by direct observation; mastitis detection was made at each farm using the California Test (CMT). At the end of the milking process two samples with an interval of 60 days were taken, each one analyzed for colony forming units (CFU), somatic cell count (SCC), percentages of protein, fat and total solids; during the interval the producers were trained in good milking practices (GMP). Statistical analyzes were performed using the Wilcoxon test. Before training, failure in the GMP was found. Significant differences for the UFC and mastitis tests before and after training were found; furthermore $24 \%$ of the mammary glands were affected by subclinical mastitis. In the hygienic milk quality, a mean CFU 6x105 and 3x105, respectively, was detected. The SCC was not significantly different, reporting average values of 630,000 and 750,000, respectively. The nutritional quality showed percentages of fat, protein and total solids, higher than those required by Colombian law. The results indicate the importance of the application of GMP on milk quality.

Key words: Somatic cells, CFU, training, quality, milking.

Palabras clave: Células somáticas, UFC, capacitación, calidad, ordeño. 


\section{INTRODUCCIÓN}

En Colombia, con el objetivo de mejorar la calidad de la leche, se expidió el decreto 616 de 2006 del Ministerio de la Protección Social, donde se establecen ciertas condiciones y prácticas para la producción primaria de leche (Ministerio de la Protección Social, 2006). El Ministerio de Agricultura y Desarrollo Rural -MADR- expide la resolución 00017 del 20 de enero de 2012, donde se establece el sistema de pago de la leche cruda al proveedor, que se basa en la calidad nutricional (porcentajes de sólidos totales) y en la calidad higiénica (Unidades formadoras de colonia, UFC), para establecer el precio por litro de leche, según los parámetros técnicos, establecidos en la resolución (MADR, 2012).

El MADR estableció las UFC, como el factor de calidad higiénica de la leche. Según la clasificación realizada por este Ministerio, establecen en la Región No. 1, los departamentos de Boyacá, de Cundinamarca, de Antioquia, de Quindío, de Risaralda, de Caldas, de Nariño, de Cauca y del Valle del Cauca, donde los conteos de UFC se deben registrar, como límite máximo, de 200.000 UFC/mL, para recibir bonificación.

El conteo de células somáticas (CCS), se emplea para determinar el estado sanitario de las glándulas mamarias de las vacas en producción; por medio de este conteo, se puede estipular el grado de infección de los cuartos individuales por vacas o por muestras generales, tomadas en tanque (Cunha et al. 2008).

Las CS, se definen como células defensoras, que viajan por el torrente sanguíneo hasta la glándula mamaria, como respuesta a algún proceso inflamatorio o de infecciones; estas células, al ingresar en la glándula mamaria, eliminan un alto porcentaje de los microorganismos presentes (Fernandes et al. 2007; Sordillo et al. 1997).

Moreno et al. (2007) reportan un alto recuento de UFC, por la influencia de la época de lluvia, que se constituye en un factor predisponente para la proliferación de patógenos en el medio ambiente; también, la no aplicación de las prácticas de ordeño pone en riesgo la calidad higiénica de la leche. Un recuento de CCS, por encima del rango permitido, debido a la presencia de mastitis subclínicas, fue encontrado por Reyes et al. (2010).

Antioquia, es el departamento con mayor producción de leche cruda del país, principalmente, los municipios ubicados en el norte y oriente. Esta última, que aporta el $18 \%$ de la producción total de este departamento, se caracteriza por la existencia, en su mayoría, de pequeños y medianos productores, que se asocian en cooperativas o asociaciones ganaderas, para la comercialización de la leche a empresas transformadoras. Éstas pagan, según su calidad higiénica y nutricional (DANE, 2011).

El municipio de Granada, ubicado en el oriente del departamento, fue una zona azotada por el conflicto armado, durante el 2000 y 2005, lo que generó el desplazamiento del $78 \%$ de su población. Desde 2007, se inició el retorno de los campesinos, lo que conllevó a la implementación de planes y de programas para reactivar el sector agropecuario. Tradicionalmente, una de las actividades económicas es la producción de leche cruda (Alcaldía de Granada, 2011).

El objetivo del presente estudio fue evaluar las prácticas de ordeño empleadas en las fincas productoras de leche y la calidad higiénica y nutricional, antes y después de la capacitación en Buenas Prácticas de Ordeño (BPO).

\section{MATERIALES Y MÉTODOS}

El estudio, se realizó en el municipio de Granada, Antioquia, donde por medio de un muestreo no probalístico, se seleccionaron diez fincas productoras de leche, pertenecientes a la Asociación de Ganaderos ASOGRAN. Se realizó un diagnóstico de las Prácticas empleadas en el ordeño, teniendo en cuenta las actividades recomendadas por el Instituto Colombiano Agropecuario ICA (Tafur \& Nieto, 2011). Se efectuó una descripción cualitativa y detallada de todo el procedimiento y se estableció cumplimiento o incumplimiento en cada una de las actividades.

Las actividades analizadas antes del ordeño fueron:

- Bienestar animal: hace referencia al trato durante el desplazamiento de los animales al sitio de ordeño y su posterior descanso, antes de iniciar la rutina de ordeño.

- Cumplimiento del horario del ordeño.

- Limpieza del establo.

- Lavado y secado de manos.

- Vacunaciones obligatorias.

Durante y después del ordeño, se evaluó:

- Pre-sellado: limpieza de los pezones con solución yodada.

- Secado de los pezones.

- Sellado: aplicación de yodo en los pezones.

- Limpieza de implementos y utensilios.

- Uso de filtrado.

Se detectó mastitis subclínicas, por medio de la prueba california para mastitis (CMT), a 130 glándulas mamarias o cuartos, antes de iniciar el ordeño; se agregó en la raqueta de prueba $5 \mathrm{~mL}$ de leche de cada cuarto y se adicionó la misma cantidad del reactivo, para el diagnóstico de mastitis (Mellenberger, 2000). Se tomaron los datos de cada finca, según la presencia de mastitis detectada; esta prueba, se 
realizó antes y después de la capacitación en BPO. Para los resultados, se empleó la siguiente ecuación:

Total de cuartos con presencia de mastitis $\mathrm{x} 100$

$\%$ de cuartos con mastitis $=\frac{\begin{array}{c}\text { Total de cuartos } \\ \text { analizados con CMT }\end{array}}{}$

Igualmente, ese mismo día, se recolectó una muestra de $50 \mathrm{~mL}$ de leche, en cada una de las fincas seleccionadas, al finalizar el ordeño de la mañana, con previa agitación, se tomó la muestra de la cantina, que contenía toda la leche del ordeño, por medio de jeringas estériles de $50 \mathrm{~mL}$ y recolectados en frascos de cierre hermético esterilizados. También, ese mismo día, se tomó una muestra al tanque de enfriamiento comunitario, de propiedad de ASOGRAN, después de la recepción de la leche de todos los productores. Luego de recolectadas las muestras, se enviaron refrigeradas en una nevera portátil, a $5^{\circ} \mathrm{C}$, al laboratorio de la empresa Productos Naturales de la Sabana S.A., ubicada en la ciudad de Bogotá, donde fueron procesadas. Los análisis efectuados para determinar la calidad higiénica fueron: UFC, que se estipuló por medio del recuento estándar en placa (INVIMA, 1998) y el CCS, determinado mediante el contador infrarrojo de células (Delaval, 2005). Para la evaluación nutricional, se establecieron los porcentajes de proteína, de grasa y de sólidos totales, mediante el analizador Milkoscope Julie C5 (Scope Electric, 2010). La primera muestra, se llevó a cabo antes de iniciar la capacitación y, la segunda, se tomó 60 días después, con los protocolos establecidos anteriormente. Esta capacitación, se realizó por medio del Servicio Nacional de
Aprendizaje SENA, en BPO, mediante el programa Jóvenes Rurales Emprendedores. Los datos recolectados del CCS, de la prueba de mastitis, de UFC y de la calidad nutricional (porcentajes de proteína grasa y solidos totales), se analizaron a través del test no paramétrico de Wilcoxon (1945) de igualdad de medias, para observar diferencias significativas, entre las pruebas antes y después de la capacitación.

\section{RESULTADOS Y DISCUSIÓN}

Diagnóstico de las prácticas empleadas en el ordeño: Para el bienestar de los animales (Figura 1), las fincas cumplieron con esta actividad; se observó a los animales al inicio del ordeño, donde realizaron un desplazamiento lento y sin presiones; de esta manera, no se genera estrés que inhiba la liberación de la leche (Ávila, 2010). La totalidad de las fincas observadas tienen establecido y cumplieron el horario para los dos ordeños: mañana y tarde. Estos resultados son contrarios a los reportados por Neira \& De Silvestri (2006), quienes indican maltrato animal durante el desplazamiento y falta de puntualidad en el ordeño. En cuanto a la limpieza del establo o áreas empleadas para el ordeño, el $20 \%$ de las fincas no cumplieron con esta condición; no procedían a levantar el estiércol generado por los animales y no tienen un plan de limpieza y de desinfección establecida. Los predios donde no se efectuó el ordeño en las áreas adecuadas para la actividad, se encuentran incumpliendo, parcialmente, la resolución 3585 de 2008, expedida por el ICA, donde se establece que los sitios empleados para el ordeño deben ser libres de encharcamientos y de material fecal. Estas áreas deben ser lavadas y desinfectadas con regularidad, para disminuir la carga bacteriana presente; esta práctica disminuye la presencia de UFC en la leche (Durán \& Duarte, 2010).

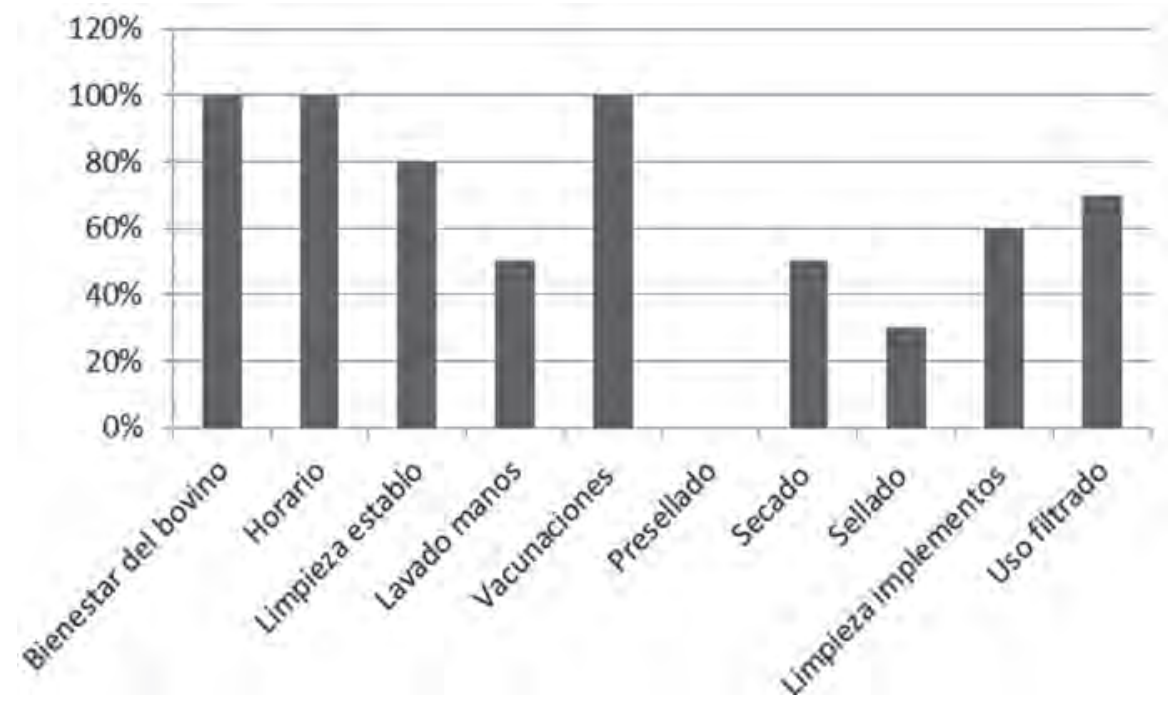

Figura 1. Porcentaje de fincas que cumplen con las actividades evaluadas en el diagnóstico inicial. 
En el 50\% de las fincas (Figura 1), los operarios no practican un lavado adecuado de manos; las fincas analizadas proceden con el ordeño de forma manual y, es por esto, que el lavado de manos debe ser aplicado, rigurosamente, por parte de los ordeñadores. En 2011, se reportó en hatos lecheros del norte de Antioquia, donde se emplea el ordeño manual, mayores conteos de UFC, comparado con el ordeño mecánico, debido a la influencia de factores, como el lavado de manos, lo que afecta la calidad de la leche (Ruiz et al. 2011), lo que también puede representar una fuente directa de contaminación de microorganismos en la leche (García \& Requelme, 2011).

En cuanto a la vacunación obligatoria (Figura 1), los productores seleccionados cumplieron con este requerimiento, debido a que la Asociación, en cada ciclo, solicita el registro único de vacunación, como requisito indispensable para la recepción de la leche, en el tanque de acopio; esto demuestra el cumplimiento parcial del decreto 616 de 2006 y de la resolución 3585 de 2008. La prevención de enfermedades, como la brucelosis, garantiza, en cierta medida, la inocuidad de la leche, para este tipo de enfermedades zoonóticas.

En ninguna de las fincas seleccionadas, se realizó el pre-sellado (Figura 1), solamente un lavado con agua. Esta desinfección favorece la calidad higiénica de la leche, debido a la disminución de microorganismos, principalmente bacterias, que se encuentran en los pezones (Durán \& Duarte, 2010).

Atehortua et al. (2013) reportan la disminución de las UFC en los pezones de las vacas, cuando se aplica el pre-sellado y concluyen que, a mayor tiempo de actuación del desinfectante, existen menores UFC en pezones. Esta actividad ha demostrado reducir bacterias, como Listeria monocytogenes, uno de los patógenos causante de infecciones alimentarias, con el mayor índice de mortalidad (Galton et al. 1984)

El 50\% de las fincas no practicaron un secado adecuado de las ubres, pues para esta actividad empleaban toallas lavables para todas las vacas. Echeverri et al. (2010) determinaron que este secado puede generar contaminación bacteriana, debido a que se utiliza en todos los cuartos y en todas las vacas, contaminando, posiblemente, cuartos que se hallan sanos. Esta es una fuente de transmisión importante de mastitis sub-clínicas; cuando se adopta el secado con trapos, se puede transmitir las bacterias generadoras de mastitis de un cuarto a otro cuarto o entre vacas (Fernandes et al. 2007). El $70 \%$ de las fincas no aplicaron el sellado al finalizar el ordeño $y$, al quedar el canal del pezón abierto, las bacterias presentes en el medio ambiente tienen la facilidad de ingresar en los cuartos e iniciar el proceso de colonización, generando mastitis sub-clínicas, que si no son detectadas a tiempo, se pueden convertir en mastitis clínicas con disminución en la producción y pérdida de la función de los cuartos afectados (Bedolla \& Ponce de León, 2008).

Respecto a la limpieza y la desinfección de los implementos y utensilios manipulados en el ordeño (Figura 1), el $40 \%$ de las fincas no procedieron a un lavado, que implique el uso de detergentes, fricción, ni desinfección al finalizar el ordeño. El $30 \%$ de las fincas no aplicó el filtrado de la leche, luego del ordeño, cuando se recolecta la leche en la cantina. El presente estudio registró un porcentaje inferior a lo reportado por Martínez et al. (2014), donde el 76,5\% de los productores no lavaban adecuadamente las herramientas, donde se depositaba la leche.

La limpieza y la desinfección de los implementos y el filtrado ayudan a conservar la calidad de la leche, debido a que estos elementos representan fuentes importantes de contaminación de microorganismos, desde el momento en que se deposita la leche hasta la recepción en el tanque de acopio; el uso del filtrado reduce la presencia de impurezas macroscópicas, que se pueden adquirir durante la rutina del ordeño (Moreno et al. 2007).

Prueba de mastitis: Para las pruebas de mastitis (Tabla 1), se encontró diferencias significativas $(p<0.05)$ (Tabla 2), entre las muestras realizadas antes y después de la capacitación, con promedios de $24,36 \%$ y $18,17 \%$, respectivamente. Esta diferencia, se podría explicar debido a la influencia de la capacitación sobre los productores, donde implementaron secado con papel y sellado a la rutina de ordeño, lo que generó la disminución de cuartos afectados por mastitis. Calderón et al. (2011) registraron un promedio inferior de $12,31 \%$ de cuartos afectados por mastitis en sistemas doble propósito, en el municipio de Montería, Córdoba. En otro estudio, practicado en Pernambuco, Brasil, se detectó un porcentaje mayor, comparado con este estudio, ya que el $39,3 \%$ de los cuartos se apreciaban afectados por mastitis en sistemas de producción, con ordeño manual (Ruiz et al. 2011). En pequeñas ganaderías con condiciones muy similares a las nuestras, en Mekelle, Etiopia, se halló el 31,57\% de cuartos afectados por mastitis clínicas y sub-clínicas (Gebrekrustos et al. 2012).

La presencia de mastitis genera disminución en la producción de leche, problemas para la salud del animal y mayor riesgo para el consumidor, debido a que algunos de los agentes patológicos presentes pueden ser zoonóticos (Vlieghe et al. 2012), afectando la salud del consumidor final, si esta leche no es procesada adecuadamente (Nada et al. 2012). Adicionalmente, representa el aumento de los costos de producción de la leche, entre un 15 y $20 \%$, como lo indican Down et al. (2013). 
Tabla 1. Porcentaje de cuartos afectados con presencia de mastitis sub-clínicas, en las 10 fincas seleccionadas.

\begin{tabular}{|l|c|c|}
\hline \multirow{2}{*}{ No. de finca } & Antes de la capacitación & Después de la capacitación \\
\cline { 2 - 3 } & \% cuartos afectados por mastitis & \% cuartos afectados por mastitis \\
\hline 1 & 33,3 & $25 \%$ \\
\hline 2 & 13,3 & $20 \%$ \\
\hline 3 & 33,3 & 14,2 \\
\hline 4 & 87,5 & 75 \\
\hline 5 & 20 & 10 \\
\hline 6 & 0 & 0 \\
\hline 7 & 25 & 0 \\
\hline 8 & 0 & 0 \\
\hline 9 & 25 & 0 \\
\hline 10 & 6,25 & 12,5 \\
\hline Promedio & 24,36 & 18,17 \\
\hline
\end{tabular}

Tabla 2. Variables analizadas mediante el Test no paramétrico de Wilcoxon para igualdad de medias, antes de la capacitación (AC) y después de la capacitación (DC).

\begin{tabular}{|l|c|}
\hline Variable & p-valor \\
\hline Porcentaje de Cuartos afectados AC y DC & 0,04206 \\
\hline Unidades Formadoras de Colonia AC Y DC & 0,001953 \\
\hline Conteo de células somáticas AC Y DC & 0,4316 \\
\hline Porcentaje de grasa AC Y DC & 0,1475 \\
\hline & 0,01367 \\
\hline Porcentaje de proteína AC Y DC & \\
\hline Porcentaje de Solidos Totales AC y DC & 0,05569 \\
\hline
\end{tabular}

Calidad higiénica de la leche: Las UFC (Tabla 3) presentaron diferencias significativas antes y después de la capacitación (p<0.05) y los promedios fueron de 699,091 y 313,364 UFC/ $\mathrm{ml}$, respectivamente. Este resultado sugiere que durante la capacitación los productores implementaron el pre-sellado, secado, lavado adecuado de manos y de utensilios; además del resultado de la disminución de la presencia de mastitis sub-clínica, luego de la capacitación, demuestra que estas actividades disminuyen, significativamente, las UFC, en la leche. Si se analizan estos resultados desde la resolución 00017 de 2012, antes de la capacitación, dos fincas recibieron bonificación por conteo de UFC; en el muestreo realizado después de la capacitación, obtuvieron bonificación cinco fincas, por mantener el conteo de UFC, por debajo de 200.000, como lo indica la resolución. Cuando se logra mantener menores conteos de UFC en la leche, se demuestra un estado óptimo de la sanidad de las ubres y de la aplicación de las buenas prácticas de ordeño, que beneficia a los procesadores y a los consumidores, debido a una vida útil, mayor de los productos lácteos (Nada et al. 2012).
El CCS no presentó diferencias significativas entre los dos muestreos (Tabla 3); este resultado difiere a lo descrito por Cuchillo et al. (2010), quienes demostraron que estas prácticas disminuyen el CCS. No solamente las mastitis pueden generar altos conteos de células somáticas, existen otros factores que pueden influir en la presencia de este tipo de células en leche, como la nutrición, el estrés asociado a las condiciones climáticas, la etapa de la lactancia, lesiones o fuertes golpes en la glándula mamaria y variaciones fisiológicas - hormonales (Hernández et al. 2008). Un alto CCS afecta la calidad de la leche para el proceso agroindustrial, debido a que poseen unas enzimas indeseables, como lipasa y plasmina (Cuchillo et al. 2010). La lipasa desdobla la grasa, produce un sabor rancio, inhibe los cultivos iniciadores del yogur y disminuye la vida comercial de la leche, mientras que la plasmina, reduce la cantidad de caseína en la leche y merma el porcentaje de rendimiento de los quesos. Estas enzimas siguen activas en la leche, aún en almacenamiento bajo refrigeración y después del proceso de pasteurización (Fernandes et al. 2007). 
Tabla 3. Unidades formadoras de colonia y conteo de células somáticas, antes y después de la capacitación.

\begin{tabular}{|c|c|c|c|c|}
\hline \multirow{2}{*}{ No. de finca } & \multicolumn{2}{|c|}{ Antes de la capacitación } & \multicolumn{2}{c|}{ Después de la capacitación } \\
\cline { 2 - 5 } & $\begin{array}{c}\text { Unidades Formadoras } \\
\text { de Colonia }\end{array}$ & $\begin{array}{c}\text { Conteo de células } \\
\text { somáticas/Ml }\end{array}$ & $\begin{array}{c}\text { Unidades Formadoras } \\
\text { de Colonia }\end{array}$ & $\begin{array}{c}\text { Conteo de células } \\
\text { somáticas/mL }\end{array}$ \\
\hline 1 & 1.070 .000 & 899.000 & 440.000 & 1.645 .000 \\
\hline 2 & 1.000 .000 & 508.000 & 550.000 & 720.000 \\
\hline 3 & 460.000 & 252.000 & 180.000 & 578.000 \\
\hline 4 & 1.230 .000 & 1.248 .000 & 810.000 & 989.000 \\
\hline 5 & 810.000 & 1.135 .000 & 520.000 & 1.424 .000 \\
\hline 6 & 310.000 & 446.000 & 70.000 & 238.000 \\
\hline 7 & 140.000 & 406.000 & 130.000 & 389.000 \\
\hline 8 & 160.000 & 462.000 & 125.000 & 350.000 \\
\hline 9 & 370.000 & 450.000 & 210.000 & 400.000 \\
\hline 10 & 1.170 .000 & 531.000 & 92.000 & 767.000 \\
\hline Tanque & 970.000 & 620.000 & 320.000 & 901.000 \\
\hline
\end{tabular}

Calidad nutricional de la leche: Los porcentajes de grasa antes y después de la capacitación no presentaron diferencias significativas (Tabla 2); los promedios fueron de 3,46\% y $3,35 \%$, respectivamente (Tabla 4). Se reportan promedios inferiores a los descritos por Calderón et al. (2012), de 3,7\%, en hatos de Montería, Córdoba. El decreto 616 de 2006 establece un porcentaje mínimo de grasa del 3,0\%, demostrando que el $90 \%$ de los hatos seleccionados producen leche dentro de la norma.
Los porcentajes de proteína antes y después de la capacitación revelaron diferencias significativas $(p<0.05)$, como se observa en la tabla 2; los promedios fueron de 3,02\% y 2,93\%, respectivamente. Calderón et al. (2012) reportan valores superiores de 3,2\% en fincas de producción doble propósito; los sólidos totales no mostraron diferencias significativas entre los dos muestreos. El presente estudio muestra niveles superiores (Tabla 4) respecto a la investigación realizada por Calderón et al. (2012), donde el promedio se

Tabla 4. Porcentajes de proteína, de grasa y de sólidos totales, antes y después de la capacitación.

\begin{tabular}{|c|c|c|c|c|c|c|}
\hline \multirow{2}{*}{ No. finca } & \multicolumn{3}{|c|}{ Antes de la capacitación } & \multicolumn{2}{l|}{ Después de la capacitación } \\
\cline { 2 - 7 } & $\begin{array}{c}\text { \% } \\
\text { Grasa }\end{array}$ & \% Proteína & $\begin{array}{c}\text { \% } \\
\text { Sólidos T }\end{array}$ & \% Grasa & \% Proteína & \% Sólidos T \\
\hline 1 & 4,23 & 2,98 & 12,66 & 3,81 & 3,01 & 12,15 \\
\hline 2 & 3,01 & 2,94 & 11,10 & 3,05 & 2,93 & 11,56 \\
\hline 3 & 3,41 & 3,20 & 12,22 & 3,25 & 3,00 & 11,69 \\
\hline 4 & 3,03 & 2,93 & 11,50 & 3,00 & 2,90 & 11,36 \\
\hline 5 & 3,71 & 3,01 & 12,11 & 3,04 & 2,66 & 10,60 \\
\hline 6 & 2,86 & 3,03 & 11,14 & 3,51 & 2,93 & 11,60 \\
\hline 7 & 3,70 & 3,09 & 12,31 & 3,30 & 3,00 & 11,78 \\
\hline 8 & 3,90 & 3,08 & 12,53 & 3,75 & 3,00 & 12,00 \\
\hline 9 & 2,90 & 3,00 & 12,15 & 2,83 & 2,94 & 11,95 \\
\hline 10 & 3,83 & 2,96 & 12,14 & 3,64 & 3,01 & 11,94 \\
\hline Tanque & 3,58 & 3,04 & $\mathbf{1 2 , 0 0}$ & 3,71 & 2,90 & $\mathbf{1 1 , 7 6}$ \\
\hline
\end{tabular}


encuentra en 11,45\%. El decreto 616 de 2006 contempla, como mínimo, los sólidos totales de leche cruda, en 11,30\%.

En las fincas, se observó porcentajes de proteína, de grasa y de sólidos totales (Tabla 4), dentro del rango permitido por el decreto 616 de 2006. Este resultado, se explica por el genotipo $\mathrm{F} 1$, resultado del cruce de razas lecheras $\mathrm{x}$ razas Cebuinas, que producen leche de calidad superior comparado con animales puros (Boland et al. 2001). El otro factor es nutricional; cuando se emplean mayores proporciones de forraje, la relación de conversión de carbohidratos fermentados en ácidos grasos volátiles, a nivel ruminal, tiene una relación directa en la glándula mamaria para producir mayores porcentajes de estos nutrientes en la leche (Pond et al. 2002; Sutton, 1989). Las leches analizadas después de la capacitación disminuyeron los porcentajes de grasa, de proteína $(p<0.05)$ y de sólidos totales, como se observa en la tabla 4, lo que se puede atribuir, probablemente, al aumento del CCS, obtenidas en este estudio, ya que al sobrepasar ciertos niveles de estas células, la calidad nutricional de la leche empieza a disminuir. Básicamente, los porcentajes de grasa que se redujeron, comparando las muestras antes y después en un promedio de $7,9 \%$, es cercano a lo descrito por Allore et al. (1997), quienes afirman que se pueden disminuir hasta en un $10 \%$. Este resultado amerita a que se realice, con mayor frecuencia, muestreos de CMT, para detección de mastitis sub-clínicas y formalizar los tratamientos correspondientes, para así evitar la alta presencia de CCS en la leche, que disminuye su calidad nutricional.

Se logra observar que la capacitación y la posterior implementación de actividades, como el uso de la prueba de mastitis california, el pre-sellado, el secado adecuado, sellado, lavado de utensilios y filtrado, logra modificar la calidad higiénica de la leche. A pesar de haber reducido la presencia de mastitis y las UFC, se recomienda continuar con jornadas y capacitaciones a los productores respecto a los factores que pueden afectar la calidad higiénica y nutricional de la leche y así lograr ajustarse a la normatividad nacional y así obtener mayores niveles de competitividad y mejores precios pagados a los pequeños y medianos productores.

Agradecimientos: Propietarios y operarios de las fincas seleccionadas en el presente estudio y ASOGRAN. Financiación: Parte de la investigación fue financiada por el CIAT Sena JRE. Conflictos de intereses: El manuscrito fue preparado y revisado con la participación de todos los autores, quienes declaramos que no existe ningún conflicto de intereses, que ponga en riesgo la validez de los resultados presentados.

\section{BIBLIOGRAFÍA}

1. ALCALDÍA DE GRANADA. 2011. Incentivo al retorno y a la reubicación. Disponible desde internet en: http://www. granadaantioquia.gov.co/indexview $=$ article $\& i d=468$ (con acceso 10/08/2012).

2. ALLORE, H.; OLTENACU, P.; ERB, H. 1997. Effects of season, herd size, and geographic region on the composition and quality of milk in the northeast. J. Dairy Sci. (USA). 80(11):3040-3049.

3. ATEHORTUA, N.; RENDÓN, L.; MONCADA, M.; MOLINA, D.; ABREÚ, A.; MORENO, F.; RAMÓN, J. 2013. Evaluación del presellado como método de desinfección de pezones en una rutina de ordeño en el norte de Antioquia. J. Agr. Anim. Sci. 02(1):34-41.

4. ÁVILA, S. 2010. Producción de leche con ganado bovino. Ed Manual moderno. México. 244p.

5. BedOlLA, C.; PONCE DE LEÓN, M. 2008. Pérdidas económicas ocasionadas por la mastitis bovina en la industria lechera. Rev. Electr. Vet. (España) 9(4):16951710. Disponible desde Internet en: http://www.veterinaria.org/revistas/redvet/n040408/040805.pdf (con acceso: 07/07/2012).

6. BOLAND, M.; HILL, J. 2001. Genetic selection to increase cheese yield. The Kaikoura experience. Australian J. Dairy Technol. 56(2):171-176.

7. CALDERÓN, A.; RODRÍGUEZ, V.; ARRIETA, G.; MARTÍNEZ, N.; VERGARA, O. 2012. Calidad fisicoquímica y microbiológica de leches crudas en empresas ganaderas del sistema doble propósito en montería (córdoba). Rev. U.D.C.A Act \& Div. Cient. 15(2):399-407.

8. CALDERÓN, A.; RODRÍGUEZ, V.; ARRIETA, G.; MÁTTAR, S. 2011. Prevalencia de mastitis bovina en sistemas doble propósito en Montería (Colombia): etiología y susceptibilidad antibacteriana. Rev. Col. Cien. Pec. 24(1):11-18.

9. CUCHILLO, Z.; DAUQUI, V.; CAMPOS, R. 2010. Factores que inciden en el recuento de células somáticas y la calidad de la leche. Ed. Unal Sede Palmira. Colombia. 54p.

10. CUNHA, R.; MOLINA, L.; CARVALHO, A.; FACURY, F.; FERREIRA, P.; GENTILINI, M. 2008. Mastite subclínica e relacao da contagem de células somáticas com número de lactocoes producao e composicao química do leite em vacas da raca holandesa. Arqu. Bras. Med. Vet. Zoot. 60(1):19-24.

11. DANE. 2011. Censo producción de leche industrial año 2011. Banco De Datos Dane. Bogotá, Colombia. 
Disponible desde internet en: http://www.dane.gov. co/files/investigaciones/agropecuario/ena/leche_industrial_2011.pdf (con acceso: 18/11/2012).

12. DOWN, M.; GREEN, C.; HUDSON, C. 2013. Rate of transmission: A major determinant of the cost of clinical mastitis J. Dairy Sci. 96(10):6127-6776.

13. DELAVAL. 2005. Manual de instrucciones. DeLaval International Tumba (Sweden). p.1-25.

14. DURÁN, J.; DUARTE, S. 2010. Diseño y aplicación de un programa de buenas prácticas de ordeño para mejorar la calidad higiénica de la leche en hatos de la Sabana de Bogotá. Rev. Cien. Anim. (Colombia). 3(1):125-132.

15. ECHEVERRI, J.; JARAMILLO, M.; RESTREPO, L. 2010. Evaluación comparativa de dos metodologías de diagnóstico de mastitis en un hato lechero del Departamento de Antioquia. Rev. Lasallista Invest. (Colombia). 7(1):49-57.

16. FERNANDES, A.; OLIVEIRA, C.; LIMA, C. 2007. Efects of somatic cell counts in milk on physical and chemical characteristics of yogurt. Int. Dairy J. (Holanda). 17(2):111-115.

17. GALTON, D; PETERSSON, W; MERRILL, D; BANDLER, D; SHUSTER, D. 1984. Effects of premilking udder preparation on bacterial population, sediment, and iodine residue in milk. J Dairy Sci 67:2580-2589.

18. GARCÍA, N.; REQUELME, N. 2011. Buenas prácticas de Ordeño y la Calidad higiénica de la Leche en el Ecuador. La Granja. 14(2):45-57.

19. GEBREKRUSTOS, M.; AFERAA, B.; TASSEW, H. 2012. Prevalencia de mastitis y su relación con factores de riesgo en granjas lecheras de pequeños propietarios en Mekelle y sus alrededores. Rev. Electr. Vet. 13(9). Disponible desde Internet en: http://www.redalyc.org/articulo.oa?id=63624399001 (con acceso $11 / 11 / 2013)$.

20. HERNÁNDEZ, R.; BEDOLLA, C. 2008. Importancia del conteo de células somáticas en la calidad de la leche. Rev. Electr. Vet. (España) 9(9):1695-1705. Disponible desde internet en: http://www.redalyc.org/articulo. oa?id=63617329004 (con acceso 15/08/2012).

21. INSTITUTO COLOMBIANO AGROPECUARIO -ICA-. 2008. Resolución 3585 Disponible desde internet en: http://www.ica.gov.co/getattachment/f6d9bf9b- defc-4b43-9d2a 88473ef99c65/2008R3585.aspx (con acceso: 14/07/2012).

22. INSTITUTO NACIONAL DE VIGILANCIA DE MEDICAMENTOS Y ALIMENTOS -INVIMA-. 1998. Manual de técnicas de análisis para el control de calidad microbiológico de alimentos para consumo humano. Santafé de Bogotá (Colombia). p.17-20.

23. MARTÍNEZ, A.; CAMBAS, A.; ENRÍQUEZ, A.; PONCE, P. 2014. Diagnóstico de buenas prácticas lecheras en una cooperativa de producción. Rev. Salud Anim. (Cuba) 36(1):14-18.

24. MELLENBERGER, R. 2000. Hoja de Información de la Prueba de Mastitis California (CMT). Depto. de Ciencia Lechera, Universidad de Wisconsin-Mádison. Disponible desde Internet en: http://milkquality.wisc. edu/wp-content/uploads/2011/09/hoja-de-informacion-de-la-pruebe-de-mastitis-california_spanish.pdf (con acceso: 20/08/2012).

25. MINISTERIO DE AGRICULTURA Y DESARROLLO RURAL -MADR-. 2012. Resolución 00017 por la cual se establece el sistema de pago de leche al proveedor. 18p. Disponible desde Internet en: http://www.hdaestrellita.com/Resoluci\%C3\%B3n\%20000017\%20 de\%202012\%20calidad\%20de\%20leche.pdf (con acceso: 20/08/2012).

26. MINISTERIO DE LA PROTECCIÓN SOCIAL. 2006. Decreto número 616. Disponible desde Internet en: http://www.agronet.gov.co/www/docs_agronet/2006103010449_decreto_616_28_02_06.pdf (con acceso 09707/2012).

27. MORENO, F.; RODRÍGUEZ, G.; MÉNDEZ, V.; OSUNA, L.; VARGAS, M. 2007. Análisis microbiológico y su relación con la calidad higiénica y sanitaria de la leche producida en la región de alto Chicamocha (Departamento de Boyacá). Rev. Med. Vet. U. Salle. 2(14):61-83.

28. NADA, S.; ILIJ, D.; IGO, T.; JELENA, M.; RUZICA, G. 2012. Implication of food safety measures on microbiological quality of raw and pasteurized milk. Food Control. 25(2):728-731.

29. NEIRA, E.; DE SILVESTRI, J. 2006. Análisis del proceso de ordeño y de la calidad higiénica de la leche utilizada en la fabricación del queso Paipa en el municipio de Paipa (Boyacá), Colombia. Rev. Invest U. Salle. 6(2):163-170. 
30. POND, W.; CHURCH, D.; POND, K. 2002. Fundamentos de nutrición y alimentación de animales. Ed. Limusa S.A. México. 635p.

31. REYES, J.; VILLAR, D.; OLIVERA, M. 2010. Evaluación de residuos de antimicrobianos por la prueba Delvotest en una cuenca lechera de Antioquia con alto índice de mastitis subclínicas. Rev. Electr. Vet. 11(12):1-10. Disponible desde Internet en: http://www.veterinaria. org/revistas/redvet/n121210/121009.pdf (con acceso $08 / 07 / 2012$ ).

32. RUIZ, A.; PONCE, P.; GOMES, G.; MOTA, R.; SAMPAIO, P.; LUCENA, E.; BENONE, S. 2011. Prevalencia de mastitis bovina subclínica y microorganismos asociados: comparación entre ordeño manual y mecánico, en Pernambuco, Brasil. Rev. Salud Anim. 33(1):57-64.

33. SCOPE ELECTRIC. 2010. Analizadores profesionales de leche Julie C5. Disponible desde Internet en: http:// www.scope-electric.com/spanish/c5.htm (con acceso $11 / 02 / 2014)$.
34. SORDILLO, L.; SHAFER-WEAVER, K.; DE ROSA, D. 1997. Immunobiology of the mammary gland. J. Dairy Sci. 80(8):1851-1865.

35. SUTTON, J. 1989. Altering milk composition by feeding. J. Dairy Sci. 72(10):2801-2814.

36. TAFUR, M.; NIETO, A. 2011. Las buenas prácticas ganaderas en la producción de leche. Editorial comunicaciones ICA. Colombia. 32p.

37. VLIEGHE, S.; FOX, L.; PIEPERS, S.; MCDOUGALL, S; BARKEMA, H. 2012. Mastitis in dairy heifers: Nature of the disease, potential impact, prevention, and control. J. Dairy. Sci. 95(3):1025-1040.

38. WILCOXON, F. 1945. Individual comparisons by ranking methods. Biometrics Bull. 1(6):80-83.

Recibido: Agosto 1 de 2013

Aceptado: Septiembre 1 de 2014

Como citar:

Silva Pulido, R.; Alzate Amelines, J.; Reyes Manosalva, C. 2014. Evaluación de las prácticas de ordeño, la calidad higiénica y nutricional de la leche en el municipio de Granada, Antioquia, Colombia. Rev. U.D.C.A Act. \& Div. Cient. 17(2): 467-475. 